\title{
Perceptions and Attitudes of Community Pharmacists' towards Patient Counseling and Continuing Pharmacy Education Programs in Iraq
}

Samer I. Mohammed ${ }^{*, 1}$, Elaf B. Dawood ${ }^{* * *}$ and Iman S. Abaas****

* Department of Clinical Pharmacy, College of Pharmacy, University of Baghdad, Baghdad, Iraq.

** Department of Pharmacology and Toxicology, College of Pharmacy, University of Baghdad, Baghdad, Iraq

*** Department of Pharmaceutics, College of Pharmacy, University of Baghdad, Baghdad, Iraq

\section{Abstract}

The pharmacist's role in the community is currently directed towards providing drug information and patient care rather than drug compounding and dispensing. Patient counseling is an essential skill for pharmacists. So as to improve the pharmacist role in the community and enhance the patient's education and counseling skills, many continuing education programs are established. The aim of this study is to assess the perceptions and tendency of community pharmacists in Iraq regarding patients counseling and continuing pharmacists' educational programs.

A cross-sectional survey was performed on a convenience sample of community pharmacists' from different governorates of Iraq from January 2017 to April 2018. Data were collected using a pretested questionnaire specifically designed from a previous study with some modification to reflect the work nature in Iraq.

The majority of pharmacists gave counseling to the patients and spent from one to five minutes in order to dispense a prescription. Approximately (53\%) concentrated on the dose of the drug during dispensing more than the duration of use $(19 \%)$ or drug indication $(21 \%)$ while approximately half of the patients, on the other hand, asked mainly on the indications of their medications also less than (32\%) asked about drug dose. Almost (47\%) of participants indicated that attending continuous pharmacist education programs can help them to improve the counseling practice furthermore, the majority of them have an optimistic attitude toward the importance of these programs for the future of their career. Most participants declared that these programs are very rare in Iraq.

This study provided a clue that the majority of community pharmacists in Iraq had an optimistic perception towards patients counseling and continuing pharmacy education programs.

Keywords: Perceptions, Patients counseling, continuous pharmacy education programs.

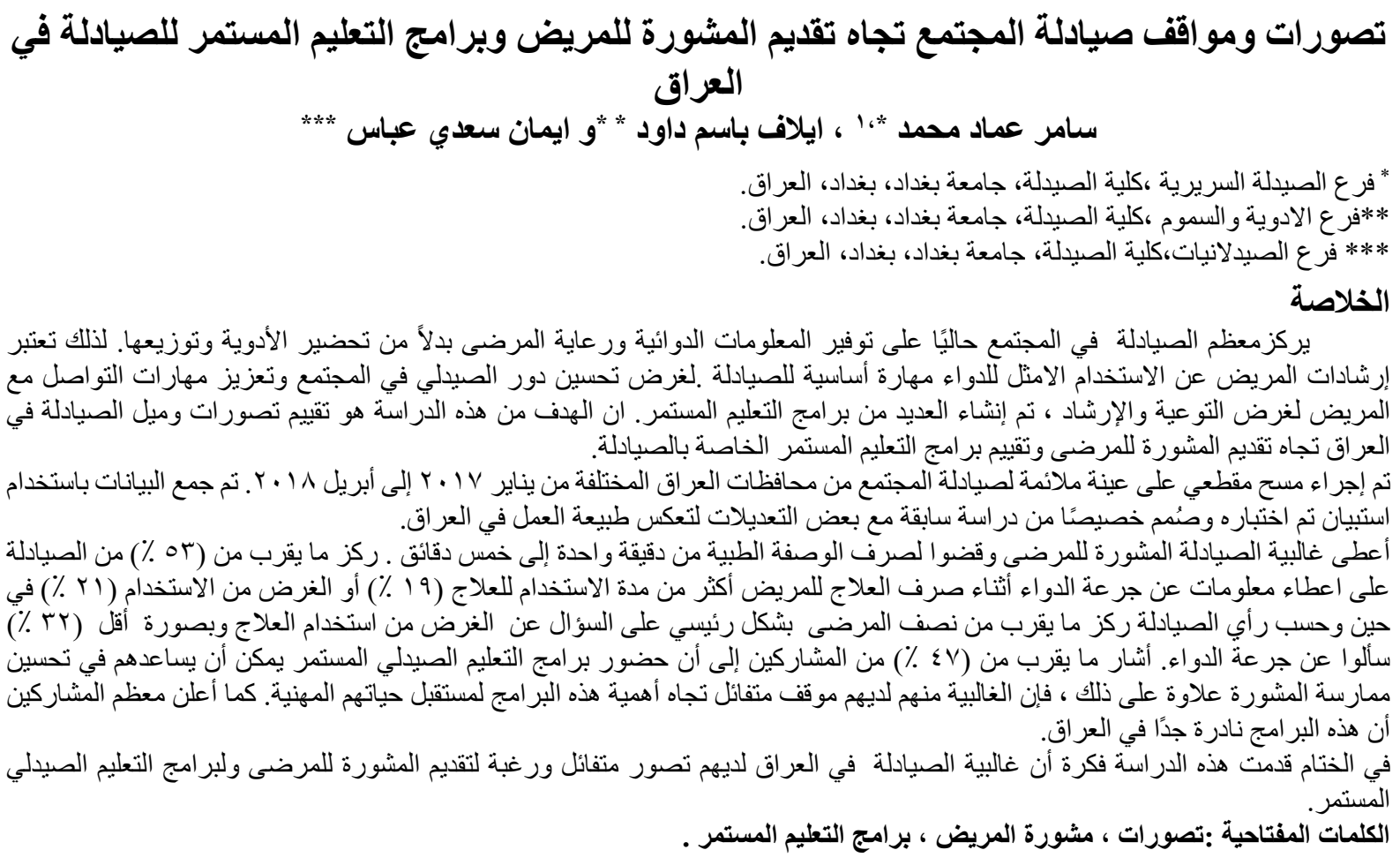

${ }^{1}$ Corresponding author E-mail: samer.jameel@copharm.uobaghdad.edu.iq

Received: $31 / 1 / 2019$

Accepted: 7/4 /2019

Iraqi Journal of Pharmaceutical Sciences 


\section{Introduction}

Most pharmacists in Iraq are working in hospitals and community pharmacies to provide pharmaceutical care services to patients ${ }^{(1)}$.

The pharmacist's role in the community has widely changed as a consequence of the expansion in the pharmacy profession worldwide. Nowadays, it is currently directed toward providing drug information and patient care rather than drug compounding and dispensing ${ }^{(2)}$.

Patient counseling is regarded as an essential skill for pharmacists to interact positively with patients besides in many countries, it is mandatory ${ }^{(3)}$

Although doctors are regarded as the first source of information about the medicines for the patients nevertheless most doctors rarely assess patients understanding when giving medications information despite the importance of doing this ${ }^{(4)}$.

This is in opposition to the pharmacists where they actively asses the response of patients which results in an increase in patient adherence, satisfaction as well as decreases in the number of medicines prescribed, medication-related problems and the cost of medication ${ }^{(5)}$.

In order to improve the pharmacist's role in the community and enhance the patient's education and counseling skills, many continuing education programs are established. The term "continuing education" has been defined as "organized learning experiences and activities in which (health care professionals) engage after they have completed entry-level academic education and training. These experiences are designed to promote the continuous development of the skills, attitudes, and knowledge needed to maintain proficiency, provide quality service or products, respond to patient needs, and keep abreast of change"(6).

Patients counseling and many pharmacy practices can be well improved when pharmacists participate in various continuous educational programs ${ }^{(7)}$.

Although the number of pharmacists in Iraq is greatly increased as a result of an increase in the number of Pharmacy Colleges in the last two decades ${ }^{(8)}$, however, there is a very limited number of continuing pharmacy education programs which does not reflect the dramatic changes in the pharmacy profession in Iraq.

The purpose of this study is to assess the attitudes of community pharmacists in Iraq concerning patients counseling and identifies the major obstacles they faced which prevent them from providing effective counseling. Furthermore, the study also evaluates the perceptions and tendency of Iraqi pharmacists to participate in continuing pharmacists' educational programs.

\section{Subjects and Methods}

A cross-sectional survey performed on a convenience sample of community pharmacists at community pharmacies in different governorates of Iraq from January 2017 to April 2018.

Data was collected using a pretested questionnaire specifically designed from a previous study with some modification to reflect the work nature in Iraq (9). The questionnaire consisted of 16 questions. The first 4 questions were collected the demographic data of community pharmacists, followed by 6 questions which related to the attitude toward patients counseling and the obstacles that face the pharmacist during counseling. While the last 6 used to measure the perception of community pharmacists towards continuing pharmacy education programs. Three questions formatted and scored on four-point (1-4) Likert scale with anchor words (Strongly agree to strongly disagree) to measure the opinion of pharmacists about continuous pharmacy education.

The study was validated by the Scientific and Ethical Committee in the College of Pharmacy, University of Baghdad. Verbal consent was obtained from all participants included in the study. The authors informed the participants about the purpose of the study at the beginning of each interview. Meanwhile, the respondents were informed that their participation was voluntary.

Statistical analysis

Statistical analysis was performed using the Statistical Package for Social Sciences software version 16 (SPSS v. 16). Pharmacists' responses were presented as frequencies and percentages. Perception of community pharmacists towards patients counseling and continuing pharmacy education program was analyzed through a scaling method.

\section{Results}

In order to evaluate the perception of Iraqi pharmacist toward patient counseling and their attitude for the continuous pharmacists' education program, a convenient sample of 263 community pharmacists from different governorates of Iraq participated in this survey. The demographic data of all participants are shown in table 1. 
Table 1. Demographic data for participants $(n=263)$

\begin{tabular}{|c|c|c|c|c|}
\hline Demographic items & \multicolumn{4}{|c|}{ Categories } \\
\hline \multirow[b]{2}{*}{$\begin{array}{c}\text { Sex } \\
\text { No. }(\%)\end{array}$} & \multicolumn{2}{|c|}{ Male } & \multicolumn{2}{|c|}{ Female } \\
\hline & \multicolumn{2}{|c|}{$91(34.60)$} & \multicolumn{2}{|c|}{$172(65.39)$} \\
\hline \multirow{2}{*}{$\begin{array}{l}\text { Age in years } \\
\text { No. }(\%)\end{array}$} & Less than 25 years & 25-35 years & 36-45years & More than 45 years \\
\hline & $96(36.50)$ & $127(48.28)$ & $31(11.78)$ & $9(3.42)$ \\
\hline \multirow{2}{*}{$\begin{array}{c}\text { Work experience } \\
\text { in years } \\
\text { No. }(\%)\end{array}$} & Less than 2 years & 2-5years & 6-10 years & More than 10 years \\
\hline & $123(46.76)$ & $77(29.27)$ & $30(11.40)$ & $33(12.54)$ \\
\hline \multirow{2}{*}{$\begin{array}{l}\text { No. of working } \\
\text { hr.at pharmacy }\end{array}$} & Less than 8 hours & 8-10hours & 11-16hours & More than 16 hours \\
\hline & $225(85.55)$ & $26(9.88)$ & $12(4.56)$ & $0(0)$ \\
\hline
\end{tabular}

More than half of the pharmacists spent from one to five minutes in order to dispense a prescription and about $(39 \%)$ consumed from five to ten minutes and only less than $(3 \%)$ take more than 10 minutes to dispense prescriptions as shown in table 2 .

Table 2. Time required to dispense a prescription $(n=263)$.

\begin{tabular}{||c|c||}
\hline $\begin{array}{c}\text { Time spent in } \\
\text { dispensing } \\
\text { prescription }\end{array}$ & No. $(\%)$ \\
\hline Less than one minute & $20(7.60)$ \\
\hline $1-5$ minutes & $134(50.95)$ \\
\hline $5-10$ minutes & $102(38.78)$ \\
\hline More than 10 minutes & $7(2.66)$ \\
\hline
\end{tabular}

More than half of the participants stated that they always provide consultation when dispensing any prescription as shown in table 3.

Table 3. Attitude to offer consultation for patients while dispensing medication $(n=263)$.

\begin{tabular}{||c|c|}
\hline Frequency & No. (\%) \\
\hline Always & $140(53.23)$ \\
\hline Frequently & $95(36.12)$ \\
\hline Occasionally & $25(9.50)$ \\
\hline Rarely & $3(1.14)$ \\
\hline
\end{tabular}

The higher percentages of pharmacists (53\%) concentrated on the dose of the drug during dispensing more than the duration of use $(19 \%)$ or drug indication $(21 \%)$ or even other information like the main side effects, drug interaction if present and the best time to take the medication which only explained by less than (7\%) of pharmacists, on the other hand, nearly half of the patients asked mainly on the indications of their medications and less than $(32 \%)$ asked about the dose of the drug (Figure1).

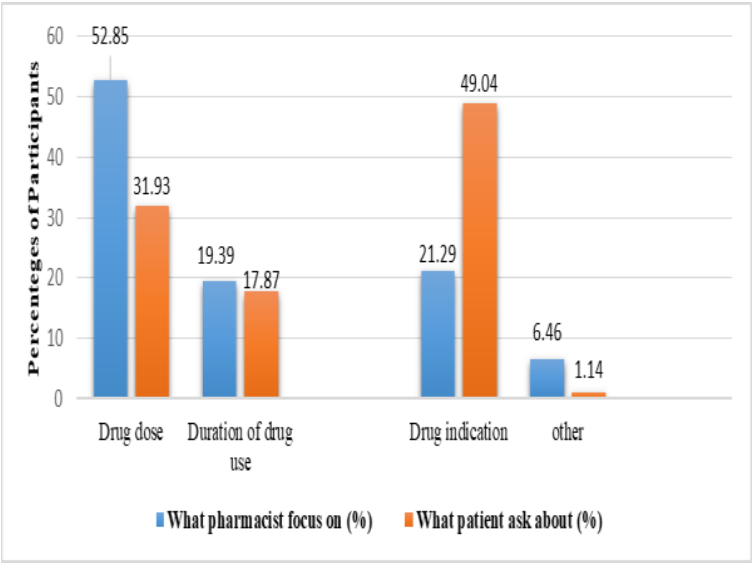

Figure 1.Variance in motivation about the consultation between pharmacists and patients as pharmacists stated $(\mathrm{n}=\mathbf{2 6 3})$.

The higher percentage of the patients listened carefully to the consultation about their medication and only less than $(3 \%)$ do not interact with the pharmacist well during the consultation process as shown in table 4 .

Table 4. Degree of attention of the patients to the medical consultation as pharmacists stated $(n=263)$.

\begin{tabular}{||c|c|}
\hline Frequency & No. (\%) \\
\hline Always & $106(40.30)$ \\
\hline Frequently & $104(39.54)$ \\
\hline Occasionally & $46(17.49)$ \\
\hline Rarely & $7(2.66)$ \\
\hline
\end{tabular}

Many participants demonstrated that absence of patient's interest in addition to the insufficient time in pharmacy is the main obstacles that face them during the consultation process (Table5). 
Table 5. Obstacles encountered the pharmacists concerning providing medical consultation $(\mathrm{n}=\mathbf{2 6 3})$.

\begin{tabular}{|c|c|}
\hline Problems & No. (\%) \\
\hline Lack of Time & $84(31.93)$ \\
\hline $\begin{array}{c}\text { Insufficient knowledge } \\
\text { and information }\end{array}$ & $42(15.96)$ \\
\hline $\begin{array}{c}\text { Lack of patient's } \\
\text { interest }\end{array}$ & $120(45.62)$ \\
\hline Other & $17(6.46)$ \\
\hline
\end{tabular}

Approximately (47\%) of participants indicated that attending continuous pharmacist education programs can help them to improve the counseling practice. Likewise, the availability of specific area for counseling is essential according to $(32 \%)$ of participants. Only about (17\%) consider that increase the number of pharmacists in one pharmacy can help. Other answers given by some pharmacists indicated that all these explanations are crucial to improve the counseling practice in addition to promoting public awareness about the importance of pharmacist's instructions as shown in table 6 .

Table 6. Pharmacists view regarding solving the obstacles concerned in providing medical consultation $(n=263)$.

\begin{tabular}{||c|c|}
\hline Strategies & No. (\%) \\
\hline $\begin{array}{c}\text { By increasing } \\
\text { pharmacists in } \\
\text { pharmacy }\end{array}$ & $44(16.73)$ \\
\hline $\begin{array}{c}\text { Attendance of } \\
\text { continuous pharmacist } \\
\text { education programs }\end{array}$ & $124(47.14)$ \\
\hline $\begin{array}{c}\text { Specify special areas } \\
\text { for providing } \\
\text { consultation }\end{array}$ & $84(31.93)$ \\
\hline Other & $11(4.18)$ \\
\hline
\end{tabular}

Only less than (5\%) of participants said that continuous pharmacist education programs available for them while more than half of the participants cleared that these programs rarely reach to Iraqi pharmacists as shown in table 7.

Table 7. Accessibility of continuous pharmacist education programs for Iraqi pharmacists $(\mathbf{n}=\mathbf{2 6 3})$.

\begin{tabular}{||c|c||}
\hline Response & No. $(\%)$ \\
\hline Frequently & $13(4.94)$ \\
\hline Occasionally & $67(25.47)$ \\
\hline Rarely & $151(57.41)$ \\
\hline Do not reach at all & $32(12.16)$ \\
\hline
\end{tabular}

Regarding pharmacists' opinion about continuing education programs and the need to establish these programs in Iraq, the result in fig. 2 showed an optimistic attitude of most pharmacists toward the importance of these programs for improving pharmacists' information in addition to providing them with the latest scientific issues and the development of pharmacy career. More than (90\%) of the contributors strongly agree or agree to launch these programs in Iraq and no one of the contributors strongly disagrees with such programs as shown in figure. 2 .

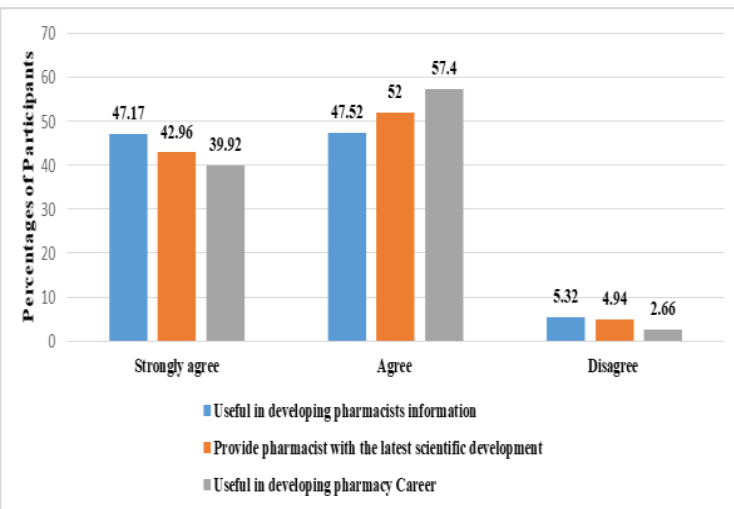

Figure 2. Pharmacists' opinion about continuing education programs $(n=263)$.

The degree of interest in attending continuous education programs for pharmacists is very high as seen in table 8 and only less than (3\%) of the participants refuse to attend these programs.

Table 8. The degree of interest in attending continuous pharmacist education programs $(\mathbf{n}=\mathbf{2 6 3})$.

\begin{tabular}{||c|c||}
\hline \hline Response & No. (\%) \\
\hline Frequently & $125(47.52)$ \\
\hline Occasionally & $106(40.30)$ \\
\hline Rarely & $26(9.88)$ \\
\hline Never & $6(2.28)$ \\
\hline
\end{tabular}

\section{Discussion}

According to previous studies, pharmacists were regarded as an easily accessible source of health care which emphases on the role of pharmacists to give the patients accurate information about their medication ${ }^{(10,11)}$.

Although work experience for most of the participants were less than two years nevertheless, the greater proportion of participant displayed a high tendency for counseling and attending continuing pharmacy education programs.

Time in community pharmacy could affect the time and quality of counseling ${ }^{(12)}$.

According to this study, the number of working hours for the higher percentages of pharmacies was less than 8 hours and this limited time may affect the 
time provided for counseling and this clearly appeared in the previous study in Saudi Arabia which showed that most of the working hours (75\%) in the pharmacies spent on dispensing and stocking and only (25\%) provided for counseling (13).

In the present study, more than half of the participant spent from (1-5) minutes with each patient to dispense a prescription. This result is similar to the previous study performed in Nepalese which indicates that the majority of pharmacists took from (1-5 ) minutes for dispensing a prescription (10), another study which assessed the Turkish community pharmacists' view about pharmaceutical care practice in Turkey, indicated only a small percentages $(22.5 \%$ ) take more than 6 minutes to counsel patients ${ }^{(14) .}$

Counseling of pharmacist is essential to enhance the patient's adherence with his medications (14). Furthermore, the World Health Organization (WHO) Good Pharmacy Practice Guidelines also suggest that the pharmacist should provide counseling ${ }^{(15)}$. The best outstanding finding of this survey was that most Iraqi pharmacists have a great tendency towards patients counseling. The greater proportions of the participants said that they regularly provide consultation when dispensing any prescription. Similarly, two other studies $(16,17)$ in different countries indicated that the pharmacists always provide counseling to their patients. During counseling, the higher percentages of participants focus on the dose of the drug than on the duration of use and to a lesser extent on indications or even other information. On the other hand, nearly half of the patients prefer to ask mainly on the indications of their medications.

In contrast, a previous study in India stated that $17 \%$ of the pharmacists give some basic information about the product and its usage method ${ }^{(18)}$.

Regarding patients' questions during counseling, the results of the present study are different from the results of a previous study in Nepal where most patients asked about the cost of the medication more than other things such as the dose or the duration of use ${ }^{(10)}$

Although the greatest proportion of the participants concluded that most patients were listening well to their counseling nevertheless, the major obstacle that faced them and reduced the effectiveness of the consultation process was a lack in some patients' interest. This made them cancel the counseling or decrease the given information. The result is similar to another study in Northwest China where the lack of patient acceptance of pharmaceutical care lead to ineffective communication between patients and pharmacists ${ }^{(19)}$.Lack of time and insufficient knowledge also can affect the counseling according to other participants in the present study that is similar to many other results in previous studies $(14,20,21)$.
Attendance of continuous pharmacist's education programs was regarded as the main strategy to solve the problem of weak counseling according to the higher proportion of the participants. The previous result was predictable as improving the knowledge of the pharmacists can assist them to improve the counseling process in a timely manner.

A comparable result was mentioned in a previous study conducted in Turkey ${ }^{(14)}$ which concluded that continuous education programs would be an important approach to enhance pharmaceutical care and counseling.

Continuous education program for the pharmacist is an effective method to improve all pharmacists knowledge after graduation ${ }^{(22)}$.

Unfortunately, these programs are very rare and not accessible for the majority of pharmacists in Iraq according to the suggestion of more than (57\%) of participants in this study. This problem is not only in Iraq but also in many other countries in the Middle East $^{(23,24)}$.

This study reveals a high attitude toward attending continuous educational programs and a promising opinion of most Iraqi pharmacists about continuing education programs. The higher percentages declared that these programs can improve pharmacists' information, in addition, to provide them with the latest scientific issues and can play a vital role in the development of pharmacy career. More than $(90 \%)$ of the contributors strongly agree or agree to launch these programs in Iraq. The great attitude of pharmacists to this program was in line with several former studies (22, 25-26).

\section{Conclusion}

This study provided a clue that the majority of community pharmacists in Iraq had an optimistic perception towards patients counseling and continuing pharmacy education programs. In addition to that, most of them showed a great tendency to contribute effectively in these programs which are absent or very rare in Iraq to improve their career and reduce the barriers toward a good effective counseling.

\section{Ethical statement}

The study and the questionnaire were validated by the local Scientific and Ethical Committee in the College of Pharmacy, University of Baghdad. Verbal consent was obtained from all participants included in the study. The authors informed the participants about the purpose of the study at the beginning of each interview. Meanwhile, the respondents were informed that their participation was voluntary and they were allowed to withdraw themselves at any point of time during the interview.

\section{Funding support disclosure statements}

No funding support received for this study. The authors themselves will support any publication fees. 


\section{References}

1. Kheir N, Zaidan M, Younes H, El Hajj M, Wilbur K, Jewesson PJ. Pharmacy education and practice in 13 Middle Eastern countries. American journal of pharmaceutical education. 2008 Sep;72(6):133.

2. Sanii Y, Torkamandi H, Gholami K, Hadavand $\mathrm{N}$, Javadi M. Role of pharmacist counseling in pharmacotherapy quality improvement. J Res Pharm Pract [Internet]. 2016 [cited 2018 Nov 17];5(2):132-7.

3. Martin-Calero M.J. BSP, Machuca M. BSP, Murillo M.D. BSP, Cansino J. BSP, Gastelurrutia M.A. BSP, Faus M.J. BSP. Structural Process and Implementation Programs of Pharmaceutical Care in Different Countries. Curr Pharm Des [Internet]. 2004 Dec 1 [cited 2018 Nov 19];10(31):3969-85.

4. Eakin MN, Brady T, Kandasamy V, Fivush B, Riekert KA. Disparities in antihypertensive medication adherence in adolescents. Pediatr Nephrol [Internet]. 2013;28(8):1267-73.

5. Stevenson FA, Cox K, Britten N, Dundar Y. A systematic review of the research on communication between patients and health care professionals about medicines: the consequences for concordance. Health expectations. 2004 Sep;7(3):235-45.

6. Austin Z, Marini A, Glover NM, Croteau D. Continuous Professional Development: A Qualitative Study of Pharmacists' Attitudes, Behaviors, and Preferences in Ontario, Canada. Am J Pharm Educ [Internet]. 2005 Sep [cited 2018 Nov 19];69(1):4.

7. McConnell KJ, Newlon CL, Delate T. The Impact of Continuing Professional Development Versus Traditional Continuing Pharmacy Education on Pharmacy Practice. Ann Pharmacother [Internet]. 2010 Oct 14 [cited 2018 Nov 19];44(10):1585-95.

8. Al-Jumaili AA, Hussain SA, Sorofman B. Pharmacy in Iraq: history, current status, and future directions. Am J Health Syst Pharm [Internet]. 2013 Feb 15 [cited 2018 Nov 19];70(4):368-72.

9. Rajiah K, Ting LC, Shan CS ML. Community Pharmacists' Perception On Patient Counseling And Continuing Pharmacy Education Program In East Malaysia. Malaysian J Public Heal Med. 2016 Jan ; 16(1):15-22.

10. Poudel A, Khanal S, Alam K PS. Perception of Nepalese community pharmacists towards patient counseling and continuing pharmacy education program: A multicentric study. J Clin Diagnostic Res [Internet]. [cited 2018 Nov 19];3(2):1408-13.
11. SI MOHAMMED. Evaluation of analgesics use and misuse by Iraqi patients in Baghdad community. Asian J Pharm Clin Res [Internet]. 2016 Jan 1 [cited 2018 Nov 21];9(1):303-307

12. Resnik DB, Ranelli PL, Resnik SP. The conflict between ethics and business in community pharmacy: what about patient counseling?. Journal of Business Ethics. 2000 Nov 1;28(2):179-86.

13. Al-Hassan MI. A look at community pharmacy practice in Saudi Arabia. Res J Med Sci. 2009;3(3):111-4.

14. Sancar M, Okuyan B, Apikoglu-Rabus S IF. Opinion and knowledge towards pharmaceutical care of the pharmacists participated in clinical pharmacy and pharmaceutical care continuing education. Turk J Pharm Sci [Internet]. 2013 [cited 2018 Nov 19];10(2):245-54.

15. World Health Organization. Joint FIP/WHO Guidelines on Good Pharmacy Practice: Standards for quality of pharmacy services. Geneva 2011. Report; 2011.

16. Haynes RB, McDonald HP, Garg AX. Helping patients follow prescribed treatment: clinical applications. Jama. 2002 Dec 11;288(22):28803.

17. SHPA Standards of Practice for Clinical Pharmacy. J Pharm Pract Res [Internet]. 2005 Jun [cited 2018 Nov 19];35(2):122-48.

18. Adepu R, Nagavi BG. Attitudes and behaviors of practicing community pharmacists towards patient counselling. Indian journal of pharmaceutical sciences. 2009 May;71(3):285.

19. Fang $\mathrm{Y}$, Yang S, Feng B, Ni Y, Zhang $\mathrm{K}$. Pharmacists' perception of pharmaceutical care in community pharmacy: a questionnaire survey in Northwest China. Health Soc Care Community [Internet]. 2010 Sep 29 [cited 2018 Nov 19].

20. Mishra $P$, Subish $P$, Upadhyay DK, Bista S, Alam K, Bhandari RB. Medication counseling center in a teaching hospital. JNMA; journal of the Nepal Medical Association. 2005;44(160):129-34.

21. Rossing C, Hansen EH, Krass I. Barriers and facilitators in pharmaceutical care: perceptions and experiences among Danish community pharmacists. Journal of Social and Administrative Pharmacy. 2002;19(2):55-64.

22. N. J, E. H, B. BIII, D. W-S. Factors affecting community pharmacy owners' attitudes toward RxSync service: A new community pharmacy practice model. J Am Pharm Assoc [Internet]. 2012;52(2):262-3. 
23. Kheir N, Zaidan M, Younes H, El Hajj M, Wilbur K, Jewesson PJ. Pharmacy Education and Practice in 13 Middle Eastern Countries. Am J Pharm Educ [Internet]. 2008 Sep [cited 2018 Nov 19];72(6):133.

24. Al-Ghamdi MS. Continuing pharmaceutical education for community pharmacists in the eastern province of Saudi Arabia. Journal of family \& community medicine. 2001 Sep;8(3):45.
25. Mehralian G, Rangchian M, Afsharmanesh G, Seifi N. Pharmaceutical care in a communitybased practice setting in Iran: Current status and future challenges. J Pharm Heal Serv Res. 2015;6(1):69-75.

26. Poudel RS, Piryani RM, Shrestha S, Chaurasiya R, Niure BP. Opinion of hospital pharmacy practitioners toward the Continuing Pharmacy Education program: a study from a tertiary care hospital in central Nepal. Integrated pharmacy research \& practice. 2017;6:157.

Baghdad Iraqi Journal Pharmaceutical Sciences by bijps is licensed under a Creative Commons Attribution 4.0 International License. Copyrights@ 2015 College of Pharmacy - University of Baghdad. 